\title{
Evaluation of Potato Genotypes for Plant and Yield Characters in Field at Dailekh
}

\author{
Binod Prasad Luitel ${ }^{1 *}$, Bishnu Bahadur Bhandari ${ }^{1}$ and Bihani Thapa ${ }^{2}$ \\ ${ }^{1}$ Horticulture Research Station, Kimugaon, Dailekh, Nepal. ${ }^{2}$ National Potato Research Program, Khumaltar, \\ Lalitpur Nepal Agricultural Research Council (NARC)
}

\section{*CORRESPONDENCE: \\ Binod Prasad Luitel \\ Horticulture Research Station, \\ Kimugaon, Dailekh, Nepal \\ Email: binodsan@yahoo.com}

ISSN : 2382-5359(Online), 1994-1412(Print)

DOI:

https://doi.org/10.3126/njst.v20i1.39380

\section{ACCESS THE ARTICLE ONLINE}

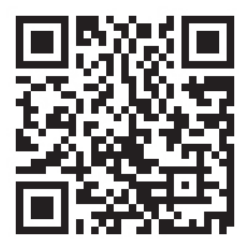

\section{CONFILICT OF INTEREST: None}

Copyright: The Author(s) 2020. This is an open access article under the $\underline{\mathrm{CC}} \mathbf{B Y}$ license.

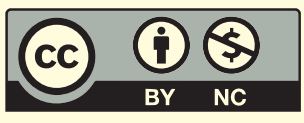

\begin{abstract}
A field experiment was conducted at Horticulture Research Station (HRS), Dailekh, in Mid-Western hills of Nepal during 2019 and 2020, to evaluate the performance of ten potato genotypes for plant, and tuber yield characters. The potato genotypes were evaluated during spring season in a randomized complete block design with three replications. The genotypes showed highly significant difference for all the traits except tuber emergence. The mean squares for the year were also significant for all the traits except tuber emergence, stem numberplant -1 and total tuber yield. The interaction between genotypes and years did not show significant differences in all the traits except stem numberplant -1. Genotype CIP392797.22 produced more marketable yield (27.5 tha -1$)$ and total tuber yield (30.2tha -1$)$ than all other genotypes. The genotype CIP392797.22 is characterized as medium maturing, oval-shaped and dark red-skinned one with shallow eye depth in the tuber, and it imparted $13.2 \%$ higher marketable yield than Kufri Jyoti (24.3 tha -1). Thus, the genotype CIP392797.22 is recommended to evaluate on-farm for the verification and up-scaling among farmers at Mid-Western Nepal.
\end{abstract}

Keywords: Potato genotypes, plant characters, tuber yield, on-farm, mid-western hill

\section{INTRODUCTION}

Potato is the world's third most important food crop after rice and wheat (FAOSTAT 2020). In Nepal, it is the fourth important crop after rice, wheat and maize but it ranks the first crop in total productivity (NPRP 2018). Potato is a staple food crop in high hills and mountains but this is a major vegetable crop for mid-hills and terai domain (NPRP 2019). Potato is also considered as an important cash crop at both hills and terai since it provides income for farmers. Moreover, potato is regarded as a high potential crop for food and nutritional security, particularly at hills, and mountains. Potato is also rich in micronutrients and vitamins and one medium-size potato boiled provides half for adult's daily requirements of vitamin C, iron, and potassium. Potato produces more energy and protein per unit area and per unit time than other food crops (Lutaladio \& Castaldi 2009). Bio-fortified potato varieties are rich in micronutrients (iron \& zinc) and antioxidants which play a significant role to address the malnutrition problem encountered in the mountain regions of Nepal. 
Potato is cultivated in all agro-ecological regions of Nepal ranging from 100 to 4,400m asl (Dhital \& Khatri 2004). It is cultivated in 193, 997 ha land with a total production of 3,112,947 tons and productivity of 16.05 tha $^{-1}$ (MoAD 2019). Mid-hilly regions of Nepal are dominant for potato and have occupied $44 \%$ of the total area of potato cultivation (NPRP 2018). Despite Nepal has favorable agro-ecology for potato production, the national productivity is still low (MoAD 2019). Lack of improved varieties, high seed demand during planting seasons and use of recycled seed tubers in the high hill sand continuous growing of old, and degenerated varieties are the principal factors for limiting production of potato in the hills (Luitel et al. 2016).

National Potato Research Program (NPRP) has developed and released eleven potato varieties so far since its establishment in 1991 (NPRP 2018), but all the varieties could not cope with the growers' demand for their desired traits of potatoes. With changing the needs of growers and industry, there is a need to develop a new variety. Cultivar development is a continuous process (Struik \& Wiersema 1999). Potato tuber yield is a complex trait that is influenced by environment and cultivar. Environmental factors such as soil temperature, moisture, light intensity, nutrient supply and proper control of disease, and pests affect the tuber yield (Struik \& Wiersema 1999). Potato genotypes bred in the tropics and temperate regions may perform differently. The performance of potato varieties varies from place to place and none of the released varieties equal the potential to perform throughout the country (Bradshaw 2007). Dailekh represents the mid-western region of Nepal and is also a potential area for potato production where many farmers use Cardinal as the improved variety for fresh tuber production. Farmers still use local varieties due to lack of access to well-adapted varieties, thus varietal diversity is very low in this region. Therefore, there is a need to evaluate different potato genotypes for their plant and yield characters, and to identify superior genotypes for the mid-western region of Nepal.

\section{MATERIALS AND METHODS}

\subsection{Study Site and Climate}

The study was conducted in field at Horticulture Research Station (HRS), Kimugaon, Dailekh district, from February to May during 2019 and 2020. The area is located at $28^{\circ} 13^{\prime} 6.18^{\prime \prime} \mathrm{N}$ and $83^{\circ} 5827.72^{\prime \prime} \mathrm{E}$ with an altitude of 1,255 masl. The mean annual rainfall ranged from 153 to $265 \mathrm{~mm}$ with the rainy season extending from June to August (HRS 2019). In the cropping season from Feb. to May, the maximum temperature varied from 18.9 to $30.9^{\circ} \mathrm{C}$ in 2019 , whereas it was varied from 20.1 to 27.9 ${ }^{\circ} \mathrm{C}$ in 2020. The minimum temperature varied from 7.4
(Feb.) to $17.7^{\circ} \mathrm{C}$ (May) in 2019 while in 2020 , it ranged from 7.9 (Feb.) to $17.6{ }^{\circ} \mathrm{C}$ (May). The pattern of rainfall was inconsistent in both the years (Fig. 1.). The climate of study area is sub-tropical type. The major soil types of the station were clay and sandy loam with medium nitrogen level and pH around 5.0 -5.5 (Luitel \& Pariyar 2017).

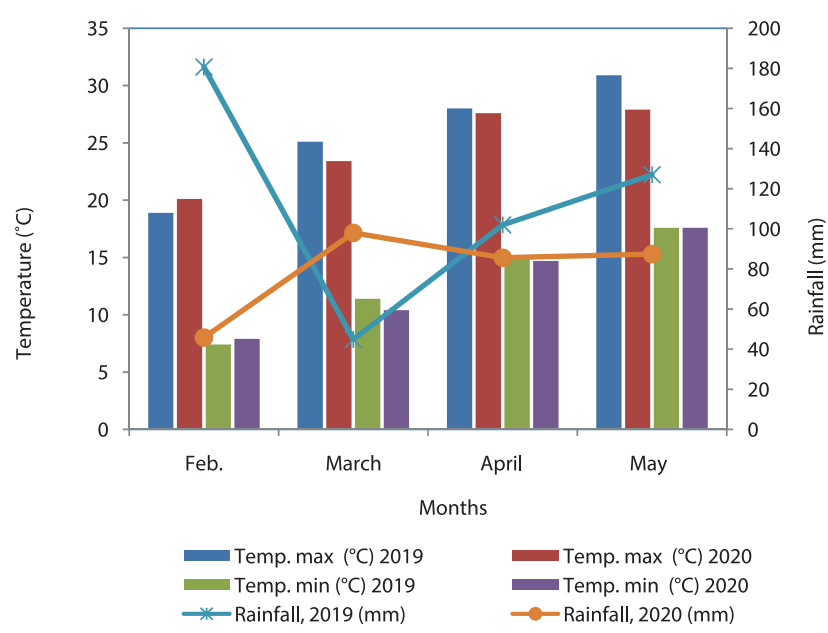

Fig. 1. Temperature and rainfall in the cropping season of potato during 2019 and 2020 at HRS, Dailekh

\subsection{Experimental Materials, Designs and Cultivation}

Seed tubers of nine potato genotypes (CIP392797.22, CIP393371.164, PRP016567.6, CIP392025.7, CIP394600.52, CIP393371.159, PRP296667.2, PRP146771.20 \& CIP303371.106) and Kufri Jyoti (a check variety) were received from National Potato Research Program (NPRP), Khumaltar, Lalitpur and planted in a randomized complete block design with three replications in field at Horticulture Research Station (HRS), Dailekh. 'Kufri Jyoti' was a popular variety in mid-hills (Luitel et al. 2017b). The soil was tilled three times and compost from the station was applied one month before planting (a) 20 tha $^{-1}\left(9.0\right.$ kgplot $\left.^{-1}\right)$. Well-sprouted medium-sized (30$50 \mathrm{~g}$ ) tubers were planted on Feb. 13, 2019, and 2020 by hand in rows $60 \mathrm{~cm}$ apart and $25 \mathrm{~cm}$ between plants within rows. Blocks were separated by $1 \mathrm{~m}$ and $50 \mathrm{~cm}$ between plots within the block. There were three rows for each genotype. Each plot was fertilized with@of 100:100:60 $\mathrm{kgha}^{-1} \mathrm{NP}_{2} \mathrm{O}_{5} \mathrm{~K}_{2} \mathrm{O}$ as recommended by NPRP (2018). Urea and DAP fertilizers were used as a source of nitrogen and phosphorus. The entire amount of phosphorus and potash and half of the nitrogen were applied at the time of planting and the remaining half of the nitrogen was topdressed at 45 days after planting. The crop was grown at irrigated condition. Cultural practices such as earthing up and weeding were carried out two times by hand during the growing period as needed. 


\subsection{DATA COLLECTION AND ANALYSIS}

Data on tuber emergence, plant uniformity, ground cover, plant height, main stem numbersplant ${ }^{-1}$, non-marketable and marketable tuber number plot $^{-1}$, total tuber number plant $^{-1}$, non-marketable and marketable tuber weight $\left(\right.$ kgplot $\left.^{-1}\right)$, marketable and total tuber yield $\left(\right.$ tha $\left.^{-1}\right)$, and the ratio of marketable tuber yield to total tuber yield were recorded. Tuber emergence was recorded by counting the emerged tubers30 days after planting. Plant uniformity was recorded at 45 days after tuber emergence using a 1 to 5 scale $(1=$ very poor, $2=$ poor, $3=$ fair, $4=$ good, and $5=$ very good). Ground cover was taken at 60 days after emergence. Each plot was assessed for the percentage of ground cover by foliage and expressed in a 1-9 scale where; $1=$ No emergence, $2=$ Less than $20 \%$ ground cover, $3=29-35 \%$ ground cover, $4=36-50 \%$ ground cover, $5=51-65 \%$ ground cover, $6=66-75 \%$ ground cover, $7=76-90 \%$ ground cover, $8=91-99 \%$ ground cover and $9=100 \%$ ground cover (Khatri \& Luitel 2014). Plant height $(\mathrm{cm})$ was measured from the soil surface to the topmost growth point of the main shoot apex when 50\% of the plants produced flowers at 80 days after planting. For the number of stemsplant ${ }^{-1}$, all the stems that emerged independently above the soil as a single stems were considered. Tubers were graded after harvesting; and tubers less than $25 \mathrm{~g}$ and diseased ones were categorized as nonmarketable, whereas tubers above $25 \mathrm{~g}$ were categorized into the marketable tubers. The marketable tuber yield was calculated using marketable tuber weight plant ${ }^{-1}$ multiplied by planting density divided by area in hectare (De Haan et al. 2014.). Total tuber yield $\left(\right.$ tha $\left.^{-1}\right)$ included weight of all tubers (marketable \& non-marketable) at the time of harvest. Marketable yield was expressed in percentage as (marketable yield/total yield)*100. In addition, maturity, tuber characters such as shape, color, skin type and eye depth were recorded by visual observation of plant foliage, and tubers as mentioned in Potato Field Book (Khatri \& Luitel 2014). Eye depth of the tuber was assessed based on indentation of the tuber at the eyes and observed visually. ANOVA was performed using Gen Stat Release 10.3 DE Software (VSN International Ltd., UK) and the correlation of quantitative characters was analyzed by IBM SPSS Statistics (Version 19.0).

\section{RESULTS}

\subsection{Yield Characters}

Genotypes had significantly affected all measured plant characters except tuber emergence (Table 1). But year affected significantly ground cover and plant height. The interaction of genotypes and years was insignificant in all the traits except stem number plant ${ }^{-1}$. The significant interaction between genotypes and year on stem number plant $^{-1}$ might be due to the genetic trait of the genotypes as well as the changing weather pattern in the experimental location.

Table 1. Mean square values of plant characters of potato genotypes for combined analysis of variance over two years (2019 and 2020) at HRS, Dailekh

\begin{tabular}{|l|c|c|c|c|c|c|}
\hline Source of variation & DF & $\begin{array}{c}\text { EMG } \\
\mathbf{( \% )}\end{array}$ & $\begin{array}{c}\text { UNIF } \\
(\mathbf{1 - 5} \text { scale) }\end{array}$ & $\begin{array}{c}\text { GC } \\
\mathbf{( \% )}\end{array}$ & $\begin{array}{c}\text { PHT } \\
(\mathbf{c m})\end{array}$ & $\begin{array}{c}\text { STPPT } \\
(\mathbf{n o .})\end{array}$ \\
\hline Genotypes $(\mathrm{G})$ & 9 & $24.77^{\mathrm{ns}}$ & $2.60^{* *}$ & $1174.3^{* *}$ & $414.4^{* *}$ & $3.61^{* *}$ \\
\hline Year $(\mathrm{Y})$ & 1 & $60.0^{\mathrm{ns}}$ & $1.81^{\mathrm{ns}}$ & $2172.0^{* *}$ & $437.94^{* *}$ & $0.04^{\mathrm{ns}}$ \\
\hline G x Y & 9 & $32.13^{\mathrm{ns}}$ & $1.81^{\mathrm{ns}}$ & $398.5^{\text {ns }}$ & $30.13^{\text {ns }}$ & $2.01^{*}$ \\
\hline Error & 38 & 28.82 & 0.45 & 201.1 & 19.4 & 0.89 \\
\hline
\end{tabular}

ns $=$ non-significant $* * *=$ significant at $5 \%$ and $1 \%$ levels, respectively. DF $=$ Degree of freedom, EMG $=$ Emergence $(\%)$, UNIF $=$ Uniformity $(1-5$ scale), $1=$ Very poor, $2=$ Poor, $3=$ Fair, $4=$ Good and $5=$ Very good, GC $=$ Ground cover $(\%)$, PHT = Plant height $(\mathrm{cm})$, and STPP $=$ Stemplant $^{-1}$ (no.)

Genotypes had a highly significant effect on nonmarketable, marketable and total tuber number plant $^{-1}$, non-marketable and marketable tuber weight, marketable and total tuber yields, and marketable yield percentage (Table 2). Year affected non-marketable and marketable tuber number, total tuber number plant $^{-1}$, non-marketable and marketable tuber weight, marketable tuber yield, and marketable yield percentage. Interaction between genotypes and year showed a significant effect on total tuber number plant ${ }^{-1}$ but it appeared non-significant in remaining traits. 
Table 2. Mean square values of yield components of potato genotypes for combined analysis of variance over two years (2019 \& 2020) at HRS, Dailekh

\begin{tabular}{|c|c|c|c|c|c|c|c|c|c|}
\hline $\begin{array}{l}\text { Source of } \\
\text { variation }\end{array}$ & DF & $\begin{array}{c}\text { NMT (no. } \\
\left.\text { plot }^{-1}\right)\end{array}$ & $\begin{array}{c}\text { MT } \\
\left(\text { no.plot }^{-1}\right)\end{array}$ & $\begin{array}{c}\text { TT } \\
\left(\text { no.plant }^{-1}\right)\end{array}$ & $\begin{array}{c}\text { NMTW } \\
\left(\text { kgplot }^{-1}\right)\end{array}$ & $\begin{array}{c}\text { MTW } \\
\left(\text { kgplot }^{-1}\right)\end{array}$ & $\begin{array}{l}\text { MTY } \\
\left(\text { tha }^{-1}\right)\end{array}$ & $\begin{array}{c}\text { TTY } \\
\left(\text { tha }^{-1}\right)\end{array}$ & $\begin{array}{l}\text { MY } \\
(\%)\end{array}$ \\
\hline Genotypes (G) & 9 & $8502.2 * *$ & $8529.0 * *$ & $23.91 * *$ & $0.864 * *$ & $32.71 * *$ & $161.55^{* *}$ & $150.26 * *$ & $173.79 * *$ \\
\hline Year $(\mathrm{Y})$ & 1 & $6406.7 * *$ & $32424.0 * *$ & $26.41^{* *}$ & $2.53 * *$ & $21.76^{*}$ & $107.5^{*}$ & $46.6^{\mathrm{ns}}$ & $438.42 * *$ \\
\hline GxY & 9 & $1451.8^{\mathrm{ns}}$ & $2085.0^{\mathrm{ns}}$ & $6.27 *$ & $0.122^{\mathrm{ns}}$ & $4.20^{\mathrm{ns}}$ & $20.74^{\mathrm{ns}}$ & $23.7^{\mathrm{ns}}$ & $14.30^{\mathrm{ns}}$ \\
\hline Error & 38 & 771.1 & 1597.0 & 2.51 & 0.099 & 2.98 & 14.7 & 14.68 & 11.66 \\
\hline
\end{tabular}

ns $=$ non-significant $* * *=$ significant at $5 \%$ and $1 \%$ levels, respectively. DF $=$ Degree of freedom, NMT $=$ Non-marketable tuber $($ no. plot $\left.^{-1}\right)$, MT $=$ Marketable tuber $\left(\right.$ no.plot $\left.^{-1}\right)$, TT $=$ Total tuber $\left(\right.$ no.plant $\left.{ }^{-1}\right)$, NMTW $=$ Non-marketable tuber weight $\left(\mathrm{kgplot}^{-1}\right), \mathrm{MTW}=$ Marketable tuber weight $\left(\mathrm{kg} \mathrm{plot}^{-1}\right), \mathrm{MTY}=$ Marketable tuber yield $\left(\right.$ tha $\left.^{-1}\right)$, TTY $=$ Total tuber yield $\left(\right.$ tha $\left.^{-1}\right)$, and MY $=$ Marketable yield $(\%)$.

\subsection{Plant and Yield Characters}

Pooled mean values of plant characters over the years are mentioned in Table 3. The highest plant uniformity (5.0) was recorded in CIP392797.22, CIP392025.7, CIP394600.52 and CIP393371.159 and the lowest (3.0) in PRP146771.20 and CIP303371.106 genotypes. Similarly, ground cover ranged from $42.0 \%$ to $81.0 \%$ with an average of $66.8 \%$. The highest plant height was recorded in PRP 016567.6(55.0cm) which was statistically similar to PRP 296667.2 (54.0cm), CIP393371.159 (54.0cm) and CIP393371.164 $(52.0 \mathrm{~cm})$. But the shortest plants were measured in genotype PRP146771.20 (30.0 cm). Genotype PRP146771.20 produced the maximum (7.0) number of stemsplant ${ }^{-1}$ which was statistically similar to CIP394600.52 (6.0), PRP296667.2 (6.0), CIP392797.22 (6.0), and CIP392025.7 (6.0).

Table 3. Growth characters of potato genotypes combined of two years (2019 \& 2020) at HRS, Dailekh

\begin{tabular}{|l|c|c|c|c|c|}
\hline Genotypes & $\begin{array}{c}\text { EMG. } \\
(\%)\end{array}$ & $\begin{array}{c}\text { UNIF } \\
(1-5 \text { scale })\end{array}$ & $\begin{array}{c}\text { GC } \\
(\%)\end{array}$ & $\begin{array}{c}\text { PTPP } \\
(\mathrm{cm})\end{array}$ \\
\hline CIP 392797.22 & 95.0 & 5.0 & 74.0 & 43.0 & 6.0 \\
\hline Kufri Jyoti (Ch) & 93.0 & 4.0 & 60.0 & 37.0 & 5.0 \\
\hline CIP 393371.164 & 94.0 & 4.0 & 73.0 & 52.0 & 5.0 \\
\hline PRP 016567.6 & 98.0 & 4.0 & 73.0 & 55.0 & 5.0 \\
\hline CIP 392025.7 & 96.0 & 5.0 & 76.0 & 48.0 & 6.0 \\
\hline CIP 394600.52 & 92.0 & 5.0 & 81.0 & 46.0 & 6.0 \\
\hline CIP 393371.159 & 98.0 & 5.0 & 79.0 & 54.0 & 5.0 \\
\hline PRP 296667.2 & 96.0 & 4.0 & 66.0 & 54.0 & 6.0 \\
\hline PRP 146771.20 & 98.0 & 3.0 & 44.0 & 30.0 & 7.0 \\
\hline CIP 303371.106 & 93.0 & 3.0 & 42.0 & 41.0 & 5.0 \\
\hline Mean & 95.3 & 3.81 & 66.8 & 46.22 & 5.65 \\
\hline F-Test & 0.568 & $<.001$ & $<.001$ & $<.001$ & $<.001$ \\
\hline P value & 6.275 & 0.784 & 16.58 & 5.156 & 1.104 \\
\hline CV (\%) & 5.6 & 17.6 & 21.2 & 9.5 & 16.7 \\
\hline
\end{tabular}

EMG. $=$ Emergence $(\%),{ }^{\mathrm{Z} U N I F}=$ Uniformity $(1-5$ scale $), 1=$ Very poor, $2=$ Poor, $3=$ Fair, 4 = Good and $5=$ Very good, $\mathrm{GC}=$ Ground cover, $\mathrm{PHT}=$ Plant height $(\mathrm{cm})$, and $\mathrm{STPP}^{-1}=$ Stem plant $^{-1}$ (no.)

The combined mean of yield characters of potato genotypes of two years is presented in Table 4. Genotypes affected significantly all the yield characters. The greatest number of non-marketable tubers was produced in genotype PRP296667.2 (195.0). Marketable tuber numberplot ${ }^{1}$ appeared the highest (241.0) in CIP392797.22, but it was statistically at par with the genotypes PRP016567.6,
CIP392025.7 and CIP394600.52. Likewise, total tuber number plant ${ }^{-1}$ was highest (14.0) in PRP296667.2, followed by CIP392297.22 (12.0) and PRP016567.6 (12.0). With regard to marketable tuber weight and yield, genotype CIP392797.22 exhibited the highest weight (12.4 kgplot $^{-1}$ ) and yield (27.5 tha $\left.{ }^{-1}\right)$, while CIP303371.106 was the lowest (12.4 tha $^{-1}$ ) yielding genotype. Genotype CIP393297.22 
produced $13.2 \%$ and $15.2 \%$ higher marketable and total tuber yield than Kufri Jyoti, respectively. Total tuber yield was produced the highest in CIP392797.22 (30.2 tha $\left.\mathrm{ta}^{-1}\right)$, followed by Kufri Jyoti $\left(26.2\right.$ tha $\left.^{-1}\right)$. Highest marketable yield was found in CIP393371.164 (94.0\%), but it was statistically similar to the genotypes CIP392025.7 (93.0\%), PRP016567.6 (92.0\%), Kufri Jyoti (92.0\%), CIP394600.52 (91.0\%) and CIP392797.22 (90.0\%), but the lowest in PRP296667.2(76.0\%).

Table 4. Yield characters of potato genotypes combined of two years (2019 \& 2020) at HRS, Dailekh

\begin{tabular}{|l|c|c|c|c|c|c|c|c|}
\hline Genotypes & $\begin{array}{c}\text { NMT } \\
(\text { no.plot }\end{array}$ & $\begin{array}{c}\text { MT } \\
\left(\text { no.plot }^{-1}\right)\end{array}$ & $\begin{array}{c}\text { TT } \\
\left(\text { no.plant }^{-1}\right)\end{array}$ & $\begin{array}{c}\text { NMTW } \\
\left(\text { kgplot }^{-1}\right)\end{array}$ & $\begin{array}{c}\text { MTW } \\
\left(\text { kgplot }^{-1}\right)\end{array}$ & $\begin{array}{c}\text { MTY } \\
\left(\text { tha }^{-1}\right)\end{array}$ & $\begin{array}{c}\text { TTY } \\
\left(\text { tha }^{-1}\right)\end{array}$ & $\begin{array}{c}\text { MY } \\
(\%)\end{array}$ \\
\hline CIP 392797.22 & 101.0 & 241.0 & 12.0 & 1.2 & 12.4 & 27.5 & 30.2 & 90.0 \\
Kufri Jyoti (Ch) & 70.0 & 198.0 & 10.0 & 0.8 & 10.9 & 24.3 & 26.2 & 92.0 \\
CIP 393371.164 & 69.0 & 170.0 & 8.0 & 0.7 & 10.7 & 23.7 & 25.3 & 94.0 \\
PRP 016567.6 & 107.0 & 230.0 & 12.0 & 0.9 & 10.4 & 23.0 & 25.1 & 92.0 \\
CIP 392025.7 & 80.0 & 220.0 & 11.0 & 0.7 & 9.8 & 21.8 & 23.4 & 93.0 \\
CIP 394600.52 & 90.0 & 198.0 & 10.0 & 0.9 & 9.5 & 21.1 & 23.1 & 91.0 \\
CIP 393371.159 & 86.0 & 182.0 & 9.0 & 0.9 & 9.3 & 20.8 & 22.8 & 91.0 \\
PRP 296667.2 & 195.0 & 183.0 & 14.0 & 1.9 & 6.4 & 14.9 & 18.7 & 76.0 \\
PRP 146771.20 & 109.0 & 131.0 & 8.0 & 1.1 & 5.8 & 12.9 & 15.4 & 84.0 \\
CIP 303371.106 & 68.0 & 130.0 & 7.0 & 0.7 & 5.6 & 12.4 & 14.0 & 87.0 \\
\hline Mean & 97.5 & 188.3 & 10.12 & 0.99 & 9.09 & 20.21 & 22.4 & 89.01 \\
P value & $<.001$ & $<.001$ & $<.001$ & $<.001$ & $<.001$ & $<.001$ & $<.001$ & $<.001$ \\
LSD (0.05) & 32.46 & 26.7 & 1.85 & 0.368 & 2.019 & 2.487 & 3.481 & 3.99 \\
CV (\%) & 28.5 & 21.2 & 15.7 & 31.7 & 19.0 & 17.6 & 17.1 & 3.8 \\
\hline
\end{tabular}

NMT $=$ Non-marketable tuber $\left(\right.$ no.plot $\left.^{-1}\right), \mathrm{MT}=$ Marketable tuber $\left(\right.$ no.plot $\left.^{-1}\right), \mathrm{TT}=$ Total tuber $\left(\right.$ no.plant $\left.^{-1}\right), \mathrm{NMTW}=$ Non-marketable tuber weight $\left(\right.$ kgplot $\left.^{-1}\right)$, MTW $=$ Marketable tuber weight $\left(\operatorname{kgplot}^{-1}\right)$, MTY $=$ Marketable tuber yield $\left(\right.$ tha $^{-1)}$, TTY= Total tuber yield $($ tha $\left.{ }^{1}\right)$, and MY $=$ Marketable yield (\%)

\subsection{Correlation Among the Plant and Yield Characters}

The phenotypic correlations among the plant and yield characters are given in Table 5. Plant emergence showed a weak correlation with ground cover, marketable tuber number, and total tuber numberplant ${ }^{-1}$. But the plant uniformity exhibited a significantly strong positive correlation with the ground cover but moderate correlation with plant height, marketable tuber number plant ${ }^{-1}$, total tuber number plant $^{-1}$, marketable tuber weight plot ', marketable yield, total yield and marketable yield percentage. Marketable tuber number plot $^{-1}$ was strongly positively correlated with total tuber number plant $^{-1}$, marketable tuber weight, marketable tuber yield, and total tuber yield, but it was moderately positively correlated with marketable yield percentage. The marketable weight was significantly positively correlated with marketable yield, total yield and marketable yield percentage.

Table 5. Phenotypic correlation of plant and yield characters of potato genotypes (combined 2019 \& 2020) at HRS, Dailekh

\begin{tabular}{|c|c|c|c|c|c|c|c|c|c|c|c|c|c|}
\hline Variables & $\begin{array}{c}\text { EMG } \\
(\%)\end{array}$ & $\begin{array}{c}\text { UNIF } \\
(1-5 \\
\text { scale })\end{array}$ & $\begin{array}{c}\text { GC } \\
(\%)\end{array}$ & $\begin{array}{l}\text { PHT } \\
\text { (cm) }\end{array}$ & $\begin{array}{l}\text { STPP } \\
\text { (no.) }\end{array}$ & $\begin{array}{c}\text { NMT } \\
\text { (no. } \\
\left.\text { plot }^{-1}\right)\end{array}$ & $\begin{array}{c}\text { MT } \\
\text { (no. } \\
\left.\text { plot }^{-1}\right)\end{array}$ & $\begin{array}{c}\text { TT } \\
\text { (no. } \\
\left.\text { plant }^{-1}\right)\end{array}$ & $\begin{array}{c}\text { NMTW } \\
(\mathrm{kg} \\
\left.\text { plot }^{-1}\right)\end{array}$ & $\begin{array}{c}\text { MTW } \\
(\mathrm{kg} \\
\left.\text { plot }^{-1}\right)\end{array}$ & $\begin{array}{l}\text { MTY } \\
\left(\text { tha }^{-1}\right)\end{array}$ & $\begin{array}{c}\text { TTY } \\
\left(\text { tha }^{-1}\right)\end{array}$ & $\begin{array}{l}\text { MY } \\
(\%)\end{array}$ \\
\hline EMG & 1.0 & $.29 *$ & $.35 * *$ & .01 & .17 & .14 & $.33 * *$ & $.26 *$ & -.02 & .12 & .13 & .12 & .03 \\
\hline UNIF & & 1.0 & $.88^{* *}$ & $.42^{* *}$ & .20 & .02 & $.66 * *$ & $.48^{* *}$ & -.03 & $.66^{* *}$ & $.67^{* *}$ & $.68 * *$ & $.39 * *$ \\
\hline $\mathrm{GC}$ & & & 1.0 & $.41^{* *}$ & .18 & -.05 & $.68 * *$ & $.45^{* *}$ & -.12 & $.64 * *$ & $.65 * *$ & $.64 * *$ & $.45^{* *}$ \\
\hline PHT & & & & 1.0 & .15 & .23 & .20 & .23 & .25 & .21 & .20 & .25 & -.01 \\
\hline STPP & & & & & 1.0 & $.36^{* *}$ & .21 & $.39 * *$ & $.32 *$ & .07 & .07 & .13 & -.21 \\
\hline NMT & & & & & & 1.0 & -.05 & $.54 * *$ & $.87^{* *}$ & $-.32 *$ & $-.32 *$ & -.18 & $-.80 * *$ \\
\hline
\end{tabular}




\begin{tabular}{|l|l|l|l|l|l|l|l|l|l|l|l|l|l|}
\hline MT & & & & & & & 1.0 & $.75^{* *}$ & -.16 & $.79^{* *}$ & $.79^{* *}$ & $.79^{* *}$ & $.52^{* *}$ \\
\hline TT & & & & & & & & 1.0 & $.41^{* *}$ & $.42^{* *}$ & $.42^{* *}$ & $.51^{* *}$ & -.07 \\
\hline NMTW & & & & & & & & & 1.0 & $-.25^{* *}$ & $-.25^{*}$ & -.09 & $-.83^{* *}$ \\
\hline MTW & & & & & & & & & & 1.0 & $.99^{* *}$ & $.98^{* *}$ & $.67 * *$ \\
\hline MTY & & & & & & & & & & & 1.0 & $.98^{* *}$ & $.67 * *$ \\
\hline TTY & & & & & & & & & & & & 1.0 & $.55^{* *}$ \\
\hline MY & & & & & & & & & & & & & 1.0 \\
\hline
\end{tabular}

* and ** indicate significance at 5 and $1 \%$ levels, respectively. $\mathrm{EMG}=$ Emergence $(\%), \mathrm{UNIF}=$ Uniformity $(1-5$ scale $), \mathrm{GC}=\mathrm{Ground}$ cover $(\%)$, PHT $=$ Plant height $(\mathrm{cm}), \mathrm{STPP}=$ Stem plant $^{-1}($ no. $), \mathrm{NMT}=$ Non-marketable tuber(no. plot $\left.{ }^{-1}\right)$, MT $=$ Marketable tuber(no. plot $\left.^{-1}\right)$ TT $=$ Total tuber(no. plant $\left.{ }^{-1}\right)$, NMTW $=$ Non-marketable tuber $\left(\right.$ kgplot $\left.^{-1}\right)$, MTW $=$ Marketable tuber weight $\left(\right.$ kgplot $\left.^{-1}\right)$, MTY $^{-}$ Marketable tuber yield $\left(\right.$ tha $\left.^{-1}\right)$, TTY $=$ Total tuber yield $\left(\right.$ tha $\left.^{-1}\right)$, and MY $=$ Marketable tuber yield $(\%)$

\subsection{Maturity and Tuber Characters}

Out of the ten, four genotypes were characterized as medium maturing types, four as late maturing types and two as early maturing types (Table 6). Tuber shapes of the genotypes were oval, round, long and round-flat. Tuber color varied from white, light red to dark red, but all the genotypes produced smooth skin type tubers. Most of the studied genotypes contained shallow eyes in the tubers.

Table 6. Tuber maturity and other tuber characters of potato genotypes (combined 2019 \& 2020) at HRS, Dailekh

\begin{tabular}{|l|l|l|l|l|l|}
\hline GENOTYPES & MATURITYz & TUBER SHAPE & TUBER COLOR & SKIN TYPE & EYE DEPTH \\
\hline CIP 392797.22 & Medium & Oval & Dark Red & Smooth & Shallow \\
\hline Kufri Jyoti $(\mathrm{Ch})$ & Medium & Oval & White & Smooth & Shallow \\
\hline CIP 393371.164 & Medium & Round & White & Smooth & Shallow \\
\hline PRP 016567.6 & Late & Oval & Light Red & Smooth & Shallow \\
\hline CIP 392025.7 & Medium & Long & White & Smooth & Shallow \\
\hline CIP 394600.52 & Late & Oval & White & Smooth & Shallow \\
\hline CIP 393371.159 & Late & Oval & Light Red & Smooth & Shallow \\
\hline PRP 296667.2 & Late & Round & White & Smooth & Shallow \\
\hline PRP 146771.20 & Medium & Round & Light Red & Smooth & Deep \\
\hline CIP 303371.106 & Early & Round flat & White & Smooth & Medium \\
\hline
\end{tabular}

MATURITY $^{z}$ Early $=<90$ days, Medium $=90-120$ days, Late $=>120$ days (Khatri and Luitel, 2014). TS $=$ Tuber shape, TC $=$ Tuber color, ST $=$ Skin type and ED = Eye depth. Eye depth was assessed visually based on indentation of the tuber at the eyes.

\section{DISCUSSION}

This study showed highly significant differences among potato genotypes which indicated the presence of genetic variation. Genotypes differed significantly in plant uniformity, ground cover, plant height, and stem number plant $^{-1}$. The variation in plant uniformity of the potato genotypes was reported by previous researchers too (Luitel et al. 2016). Genotypes differ genetically in their growth habit (Tessema et al. 2020). Ground cover is also determined by the growing condition, planting time and tuber bulking behavior of genotypes, and in this study, late cultivars had higher ground cover than early maturing cultivars. Deblonde and Ladent (2001) reported the reduced plant height in late cultivars. In contrast, the late cultivars identified in this study had the highest plant height. Besides, the differences in plant height among the genotypes may be caused by genetics of the plant as well as the quality of planting materials (Eaton et al. 2017). The variation in stem number plant ${ }^{-1}$ among the genotypes might be due to genetic traits (Nielson et al. 1989). It is also affected by the length of the pre-sprouting period (Allen 1978), size of the seed tuber (Eaton et al. 2017) and physiological age (Irritani 1698). Year affected particularly on ground cover and plant height indicating changing temperature and rainfall patterns during the crop season. The significant interaction of genotypes and years found in this study might be due to environmental fluctuation that could be affecting the number of stemsplant ${ }^{-1}$ and a similar result was reported by Fantaw et al. (2019). 
Genotypes showed significant variation in non-marketable and marketable tuber numbers, total tuber numbers, nonmarketable and marketable tuber weight, marketable, and total tuber yield, and marketable yield percentage. The significant variation in tuber number plant $^{-1}$ might be due to genotypic factors. Lahlou et al. (2003) reported that tuber number was more affected in early maturing genotypes, which was close to our result. Seifu and Betewulign (2017) also reported a significant difference in total tubers plant ${ }^{-1}$ among potato varieties. Tuber weight is an important yield component of potato that contributes to total tuber yield (Morena et al. 1994; Luitel et al. 2017a). Variation in marketable tuber weight among the genotypes may be due to genetics. Besides genotypes, management practices, seed quality and agro-ecological condition of the experimental site also affect the weight of tubers (Eaton et al. 2017). The number and size of potato tubers are economically important characters for marketing, human consumption and seeds for planting (Kirkman 2007). Tuber size required for consumers depends on the ease of handling for household purposes, and our study showed that genotype CIP392797.22 contained better marketable tuber number and weight. Better plant uniformity, canopy cover, stem number plant $^{-1}$, marketable tuber number and total tuber number plant ${ }^{-1}$, and marketable tuber weight might have contributed to higher yield in genotype CIP392797.22. Clone CIP392797.22, a red-skinned, high yielding and moderately resistant to late blight, was released as 'Yusi Maap', and it is a micronutrient (iron and zinc) dense variety (Bajgai et al. 2018). Tuber yield is a complex trait, affected by genotype and environmental factors (Struik \& Wiersema, 1999). Luitel et al. (2016) reported a marketable tuber yield variation of 7.6 to 24.0 tha $^{-1}$ at high hills of Nepal and similar tuber yield variation were reported on potato by different researchers in Nepal (Luitel et al. 2017a; Gainju et al. 2019). In addition to the genotypic effect, differences in tuber size, plant spacing and weather variations could have caused the yield variation among the genotypes (Masarirambi et al. 2012). The present study showed that marketable yield percentage among potato genotypes varied from 76.0 to $94.0 \%$, but in the study of $\mathrm{Hu}$ et al. (2017), they observed $73.5 \%$ marketable yield percentage.

Plant uniformity, ground cover, marketable tuber number, total tuber number and marketable tuber weight exhibited a significant positive association with marketable and total tuber yields, and these can be used to improve tuber yield by making simultaneous improvement of those traits. The strong positive correlation between tuber weight and yield was also reported by Khayatnezhad et al. (2011). The number of stems plant ${ }^{-1}$ showed moderate correlation with tuber number, but it did not show any correlation with tuber yield, and similar results were reported by Kaur et al. (2017). The positive correlation between tuber size and tuber yield was also reported by Yuan et al. (2016). Tuber maturity is influenced by the environment, whereas tuber characters, such as color, skin type, and eye depth remain stable over the environments (Struik \& Wiersema 1999). Generally, farmers prefer early to medium maturing and red-skinned potato genotypes in mid-western hills. Our study revealed that the clone CIP392797.22 having a medium maturing type. Variation in tuber shape, color and eye depth was observed in the studied genotypes. Tuber shape, skin texture and flesh color, and eye depth are quality parameters that influence consumer's choices (Pandey et al. 2000). The skin color in potato tuber is controlled by a genetic system that controls the presence and absence of red and blue pigments (Van Eck et al. 1994). Tubers round to oblong in shape are suitable for chips making, and long oval to very long oval-shaped tubers are best for making French fries (Pandey et al. 2000). The deep eye is not a desirable trait for peeling or potato processing (Yuan et al. 2016) and in general, consumers prefer potatoes having shallow to medium eye depth (Kabira \& Lemaga 2006). The variation in eye depth in potato genotypes was reported by previous researchers (Luitel et al. 2017b; Gainju et al. 2019) too.

\section{CONCLUSION}

In this study, genotypes showed a significant variation in plant and yield characters. Out of the ten genotypes tested, CIP392797.22 (UNICA) performed better in plant uniformity, ground cover, stem number plant $^{-1}$, and marketable and total tuber number. CIP392797.22 also produced higher (13.2\%) marketable and total yields than commercial check variety Kufri Jyoti. Clone CIP392797.22 contained more number of marketable tubersplot ${ }^{-1}$ which is desirable for market. In addition to this, this clone has a medium maturing type that can be fit in the maize based cropping system of the mid-hills. Clone having red skin, oval-shaped tuber with shallow eye depth could have advantage for farmers to fetch it in high price in the market. CIP392797.22 is also a micronutrient ( $\mathrm{Zn}$ and Iron) dense genotype. Scaling-up this genotype at an on-farm level can help to maximize potato productivity which will help to solve the food and nutritional security problems of mid-western Nepal.

\section{ACKNOWLEDGMENT}

This research was funded by NARC under the MultiLocation Research Project of HRS, Dailekh. In this work, Bihani Thapa provided the research materials of potato from NPRP, Bishunu Bahadur Bhandari helped to observe data and Dr. Binod P. Luitel designed the experiment in the field, analyzed the data and prepared the manuscript. 


\section{REFERENCES}

1. Allen, E.J. 1978. Plant density, In: Harris PM (Ed.), The potato crop. The scientific basis of improvement, Chapman and Hall, Ltd., London. p. 278-326.

2. Bajgai, Y., T. Dochen, P. Wangchuk, S. de Haan, M.S. Kadian, T. Z. Felde, M. Bonierbale, M. Lefebvre, L. Zang, S. Arya, S. Sangay, T. Gyeltshen and N. Wangdi, 2018. Participatory varietal selection of potato and agronomic performance with farmers' feedback on new variety. Bhutanese Journal of Agriculture 1(1): $1-12$.

3. Bradshaw, J.E. 2007. Potato Breeding Strategy. In: Potato Biology and Biotechnology: Advances and Perspectives (eds), Vreugdenhil, D., Bradshaw, J., Gebhardt, C., Govers, F., Mackerron, DKL, Taylor, MA and Ross, HA. Elsvier Ltd., Amsterdam, Netherlands, pp. 157-178.

4. De Haan S., A. Forbes, W. Amoros, M. Gastelo, E. Salas, V. Hualla, F. De Mendiburu, and M. Bonierbale. 2014. Procedure for standard evaluation and data management of advanced potato clones. Module 2. Healthy tuber yield trials. International Cooperators' Guide, Lima (Peru). International Potato Center: 14p.

5. Deblonde, P.M.K. and J.F. Ledent. 2001. Effects of moderate drought conditions on green leaf number, stem height, leaf length, and tuber yield of potato cultivars. Eur. J. Agron 14:1-41.

6. Dhital, B. K. and B.B. Khatri. 2004. Potato production in Nepal (Nepali Version). Shradha Press, Lagankhel, Lalitpur, Nepal.

7. Eaton, T. E., A.K. Azad, H. Kabir and A.B. Siddiq. 2017. Evaluation of six modern varieties of potatoes for yield, plant growth parameters and resistance to insects and diseases. Agri Sci. 8:1315-1326.

8. Fantaw, S., A. Ayalew, D. Tadesse, Z. Medhin and E. Agegnehu. 2019. Evaluation of potato (Solanum tuberosum L.) varieties for yield and yield components. Journal of Horticulture and Forestry. 11: 48-53.

9. FAOSTAT. 2020. FAO Statistical Year Book for Asia and Pacific Food and Agriculture. http://faostat.fao.org

10. Gainju, A., A.K. Shrestha, S. Manandhar and K.P. Upadhyay. 2019. Performance of promising potato clones for growth and yield characters in Bhaktapur, Nepal. North American Academic Research. 2:132142.

11. HRS, 2019. Annual Report 2075/76 (2018/2019). (Binod Prasad Luitel Ed.), Horticulture Research Station, NARC, Kimugaon, Dailekh, Nepal.
12. Hu Q, N. Yang, F. Pan, X. Pan, X. Wang, and P. Yang. 2017. Adjusting sowing dates improved potato adaptation to climate change in semiarid region, China. Sustainability. 9:615.

13. Iritani, W.M. 1968. Factors affecting aging (degeneration) of potato tubers used as seed. Am Potato J. 45:111-116.

14. Kabira, J.N. and B. Lemaga. 2006. Potato processing: Quality evaluation procedures for research and food industries applications in East and Central Africa. Kenya Agricultural Research Publication, Nairobi, Kenya.

15. Kaur, R.P., B. Chaudhary and W. Alam. 2017. Associations among yield and yield contributing traits of potato (Solanum tuberosum) in north-western plains of India. Indian Journal of Agricultural Sciences. 87: 1409-11.

16. Khatri, B.B. and B.P. Luitel. 2014. Field book for standard evaluation of potato and sweet potato germplasm. Government of Nepal, Nepal Agricultural Research Council (NARC), National Potato Research Programme, Khumaltar, Lalitpur, Nepal: Pp. 1-70.

17. Khayatnezhad, M., R. Shahriari, R. Gholamin. S. Jamaati-e-Somarin and R. Zabihi-e-Mahmoodabad. 2011. Correlation and path analysis between yield and yield components in potato (Solanum tuberosum L.). Middle-East Journal of Scientific Research. 7:17-21.

18. Kirkman, M.A. 2007. Global markets for processed potato products. In: Potato Biology and Biotechnology: Advances and Perspectives (eds). Vreugdenhil D., Bradshaw J., Gebhardt C., Govers F, Mackerron D.K.L, Taylor M.A. and Ross H.A. Elsevier Ltd. Amsterdam, Netherlands, pp. 27-43.

19. Lahlou, O., S. Ouattar and J.F. Ledent, 2003. The effect of drought and cultivar on growth parameters, yield and yield components of potato. Agronomie. 23: 257268.

20. Luitel , B.P., B.B. Khatri, D. Choudhary, P. Karki and Y.P. KC. 2017b. Evaluation of medium maturing cv. 'Kufri Jyoti' under short day condition. Pages 214219 in I.P. Gautam, S.L. Shrestha, G.D. Subedi, D.R. Bhattarai, T.P. Gotame and K.P. Upadhyay, editors. Proceedings of the Ninth National Horticulture Workshop, May 31-June 1, 2017, Khumaltar, Lalitpur, Nepal. 
21. Luitel, B.P, L. Laxmi, B.B. Khatri, D. Choudhary, R.K. Giri, M.S. Kadian, S. Arya, R. Dhakal, and M. Bonierbale. 2016. Evaluation of micro-nutrient rich potato genotypes in temperate conditions of Nepal. Potato J. 43: 138-145.

22. Luitel, B. P., and K. Pariyar. 2017. Soil physic-chemical properties of Horticulture Research Station. Annual Report (2016/2017). NARC, Kimugaon, Dailekh, Nepal.

23. Luitel, B.P., B.B. Khatri, L. Lama, R. Dhakal, K. Khadka, D. Choudhary, S. Arya, M. Bonierbale and M.S. Kadian, 2017a. Yield Evaluation of nutrient-rich potato clones in high hills of Nepal. Journal of Nepal Agricultural Research Council. 3:06-14.

24. Luitel, B.P., B.B. Khatri, S.L. Shrestha, D. Choudhary, I. P. Gautam, K..P. Upadhyay, S. Ghimire and S. Pandey. 2017b. 'PRP 25861.1' : A high yielding, early maturing, red skinned promising potato clone for the hills of Nepal. Nepalese Horticulture. 12:46-53

25. Lutaladio, N. and L. Castaldi. 2009. Potato: The hidden treasure. J. Food. Comp. Analysis. 22: 491-493.

26. Masarirambi, M.T., F.C. Mandisodza, A.B. Mashingaidze and E. Bhebhe. 2012. Influence of plant population and seed tuber size on growth and yield components of potato (Solanum tuberosum). Int $J$ Agric Biol. 14:545-9.

27. MoAD. 2019. Statistical information on Nepalese Agriculture 2018/19 (2075/76). Ministry of Agriculture and Livestock Development, Singhadurbar, Kathmandu, Nepal.

28. Morena, I., A. Guillen and L.F.G. Moral, 1994. Yield development in potatoes as influenced by cultivar and the timing and level of nitrogen fertilization. American Journal of Potato Research. 7:165-173.
29. Nielson, M., W.M. Iritani and L.D. Weiler. 1989. Potato seed productivity; factors influencing eye number per seed piece and subsequent performance. Am. J. Potato Res. 66:151-160.

30. NPRP, 2018. Annual Report 2074/75 (2017/18). (Kalika P. Upadhyay, Ed.), National Potato Research Program, NARC, Khumaltar, Lalitpur, Nepal.

31. NPRP, 2019. Annual Report 2075/76 (2018/19). (Kalika P. Upadhyay, Ed.), National Potato Research Program, NARC, Khumaltar, Lalitpur, Nepal.

32. Pandey, S.K., G.S. Shekhwat and D. Sarkar. 2000. Quality attributes of Indian potatoes for export: priorities and possibilities. Journal of Indian Potato Association, 27:103-111.

33. Seifu, F. and E. Betewulign. 2017. Evaluation of potato (Solanum tuberosum L.) varieties for yield attributes. Journal of Biology, Agriculture and Healthcare. 7:1522.

34. Struik, P.C. and S.G. Wiersema. 1999. Seed potato technology. Wageningen Pers, Wageningen. p.51.

35. Tessema, L., M, Wassu and T. Abebe. 2020. Evaluation of potato (Solanum tuberosum L.) varieties for yield and some agronomic traits. Open Agriculture. 5:63-74

36. Van Eck, H.J., J. Jacobs, P. Stam, J. Ton, W.J. Stiekema and E. Jacobsen. 1994. Multiple alleles for tuber shape in diploid potato detected by qualitative and quantitative genetic analysis using RFLPs. Genetics. 137:303-309.

37. Yuan, J., A. Murphy, D.D. Koeyer, M. Lague and B. Bizimungu. 2016. Effectiveness of the field selection parameters on potato yield in Atlantic Canada. Can. $J$. Plant Sci. 96: 701-710. 